\title{
Comparative Evaluation of Sugar based versus sugar free Oral liquid preparation in Medicare
}

\author{
Dr.Avinash Shankar ${ }^{1 *}$, Dr.Amresh Shankar ${ }^{2}$, Dr Anuradha Shankar ${ }^{3}$ \\ ${ }^{I} M D$ (Internal Medicine), DNB(E\&M);PhD, Postgraduate in Endocrinology \& Metabolism(AIIMS-Delhi) \\ ,Chairman ,Institute of Applied Medicine,National Institute of Health \& Research \\ , Warisaliganj(Nawada)Bihar, 805130 \\ ${ }^{2}$ BAMS(BRABU);MHA ,Hon Director, Aarogyam Punarjeevan ,Ram Bhawan, Ara Garden, Jagdeopath,Baily \\ Road,Patna 14 \\ ${ }^{3}$ BAMS(BRABU), ExDirector, Centre For Indigenous Medicine \& Research, Senior Research Fellow cum \\ Medical Officer,Regional Institute of Ayurveda Research, Itanagar (Arunachal) \\ *Corresponding Author: Dr. Avinash Shankar, MD(Internal Medicine), DNB(E\&M);PhD , \\ Postgraduate in Endocrinology \& Metabolism(AIIMS-Delhi), Chairman, Institute of Applied \\ Medicine,National Institute of Health \& Research, Warisaliganj(Nawada)Bihar,805130
}

\begin{abstract}
Oral liquid therapeutic is the most compliable form of therapeutics and a need for neonates to geriatrics where palatability is prime index but sugar based preparation poses threat like drug resistance, decline in self defence and predisposes for erythrocyte toxicity due to persisting infection as compared to oral liquid preparation free of sugar which promote early onset of relief of presentation without any evident alteration in therapeutic absorption .
\end{abstract}

Thus, to check recurrence, relapse, drug resistance and potentiate therapeutic efficacy without any alteration in self defence. Oral liquid preparation free of sugar is preferred either as therapeutics or adjuvant.

Keywords: Compliable, palatability, drug resistance, self-defence, absorption alteration, absorption, recurrence, relapse, drug resistance, adjuvant)

\section{INTRODUCTION}

Increasing non dietary products in the food, water and even in soil due to increasing trends of chemicals, fertilizers, pesticides and hormones for maximum yield, thus essential mineralo vitamin and trace elements gets depleted and concentration of competitive inhibitors of the vitamin minerals get increased and results in altered metabolic process either due to potent toxicity of liver ,pancreas and reticulo endothelial system .

Clinical evaluation of patients suffering with various recurring manifestation of varied origin reveals increasing trend of hyperglycaemia and glycosuria.

In addition random observation of failure of sugar based oral therapeutics to achieve clinical efficacy at par with sugar free oral preparation, rather sugar based preparation predispose for disease chronicity .

Considering the fact, a study was planned to evaluate the clinical efficacy of sugar free oral liquid preparation versus sugar based in day to day Medicare

\section{Materials ANd Methods}

\section{Design of the Study}

Parallel group comparative evaluation

\section{Objective of the Study}

Evaluation of therapeutic significance of Sugar free therapeutics over sugar based preparation and their safety profile in various common clinical conditions 


\section{Material}

1000 patients of varied clinical presentation attending various clinics of National Institute of Health \& Research having preference for oral liquid preparation were selected for the study .

Exclusion criteria : Patient suffering with Diabetes mellitus are excluded .

\section{Methods}

Selected patients Or their parent Or attendant were thoroughly interrogated,clinically examined and investigated to establish the diagnosis and pre therapy and post therapy bio parameters are assessed to adjudge the safety profile .

For comparative clinical evaluation of oral liquid therapeutics in sugar base versus sugar free base ,selected patients were classified in three equal group constituting 333 patients in each Group A and B while 334 in group $\mathrm{C}$.

Each group patients were advocated :

Group A (333) : Sugar free therapeutics or adjuvant

Group B (333) : : Sugar based therapeutics Or adjuvant

Group C (334) : Sugar free oral liquid

Patients were assessed as per following index of assessment -

Duration to achieve clinical improvement and clinicopathological outcome

Status of Clinical presentations

Adjuvant required

Hospital stay /duration of treatment to achieve cure

Post withdrawal status

Growth and development

Onset of mile stone

Assessment of safety profile :

To asses or adjudge safety profile following bio parameters are considered

Hepatic : SGOT;SGPT,Serum bilirubin, urobilinogen

Renal : urine albumin ,blood urea, serum creatinine ,urine culture

Haematological : Haemoglobin ,

Immunological : Recurring Or persisting infection (Blood culture /Urine culture)

\section{OBSERVATION}

Selected patients were of age group neonate to 55 years and are 630 male and 370 female, though $20 \%$ cases were of age below 5 years and $6.4 \%$ were of age $>50$ years .

Table Showing distribution of patients as per age and sex

\begin{tabular}{|c|c|c|c|}
\hline \multirow{2}{*}{ Age group in year } & \multicolumn{3}{|c|}{ Number of patients } \\
\cline { 2 - 4 } & Male & Female & Total \\
\hline$<1-5$ & 22 & 12 & 64 \\
\hline $5-10$ & 36 & 26 & 59 \\
\hline $10-15$ & 34 & 25 & 66 \\
\hline $15-20$ & 42 & 24 & 108 \\
\hline $20-25$ & 70 & 38 & 136 \\
\hline $25-30$ & 80 & 56 & 116 \\
\hline $30-35$ & 76 & 40 & 105 \\
\hline $36-40$ & 70 & 35 & 136 \\
\hline $40-45$ & 90 & 46 & 106 \\
\hline $45-50$ & 70 & 36 & 72 \\
\hline $50-55$ & 40 & 32 & \\
\hline
\end{tabular}


Pie diagram showing male female composition

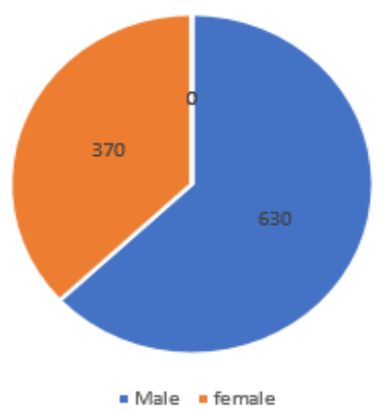

Predominant presenting feature was diarrhoea, Pregnancy, general debility hypertension, arthritis, urinary tract infection, bone injury and post tube ligation syndrome were also common.

Table Showing distribution of patients as per clinical presentation:

\begin{tabular}{|l|l|}
\hline Clinical condition & Number of patients \\
\hline Diarrhoea & 200 \\
\hline Pregnancy & 120 \\
\hline General debility & 100 \\
\hline Hypertension & 90 \\
\hline Joint pain & 70 \\
\hline Urinary tract infection & 77 \\
\hline Recurrent Pruritis & 90 \\
\hline Respiratory disease & 110 \\
\hline Surgical wounds & 48 \\
\hline Bone injury & 42 \\
\hline Post ligation syndrome & 53 \\
\hline
\end{tabular}

Group A(Sugar free therapeutics) and Group B (Sugar based therapeutics) constitute 333 patients in each , while Group C ( sugar free non therapeutics) 334 patients of varied clinical presentation .

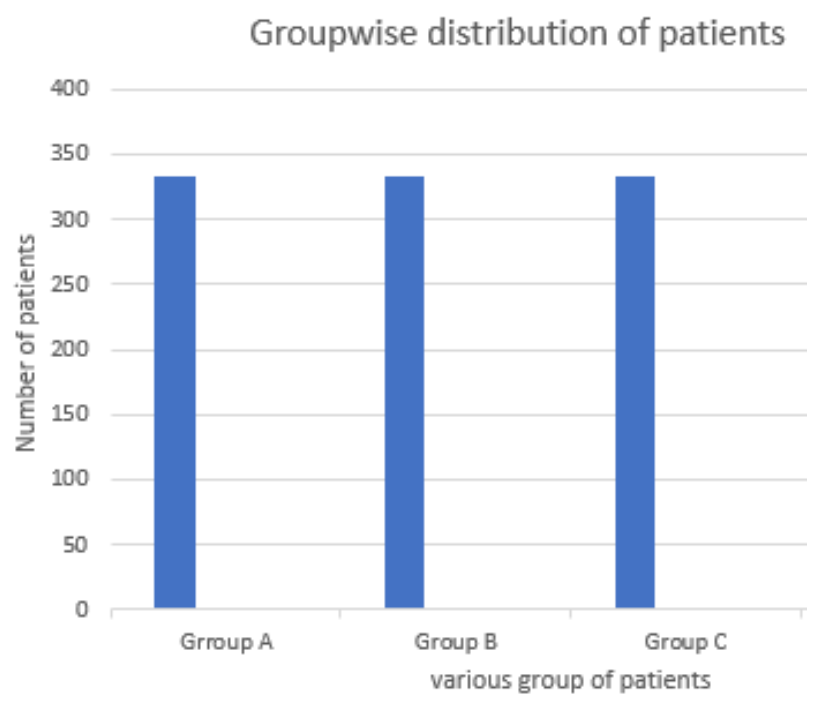

\section{RESULT}

\section{In Diarrhoeal Disease Management}

All cases taking sugar free anti diarrhoeal had marked improvement in the mean duration of 4 hours whether patient taking sugar based anti diarrhoeal only $40 \%$ had clinical improvement in mean duration of $10 \mathrm{hrs}$ but no significant effect was observed in control group .

No untoward effects was observed in patients of group A but $60 \%$ patients of group B having initial clinical response, $20 \%$ of them had marked exacerbation and needed adjuvant therapy .In post therapy state $40 \%$ presented with mucous colitis , $20 \%$ with UTI and $40 \%$ with abdominal distension whether none of group $\mathrm{C}$ had neither exacerbation nor abdominal discomfort . 


\begin{tabular}{|l|l|l|l|}
\hline Particulars & Group A & Group B & Group C \\
\hline $\begin{array}{l}\text { Decline in frequency of } \\
\text { stool }\end{array}$ & All & & \\
\hline Duration required of & None & & \\
\hline $\begin{array}{l}\text { Exacerbation } \\
\text { presentation }\end{array}$ & None & & \\
\hline $\begin{array}{l}\text { Initial relief with } \\
\text { exacerbation }\end{array}$ & None & & \\
\hline Mucous colitis discomfort & None & & \\
\hline Urinary tract infection & None & & \\
\hline Abdominal disced & & \\
\hline
\end{tabular}

Pregnant mothers taking sugar free vitamin mineral supplement delivered healthy baby through normal parturition and without any congenital defect whether of group B only 50\% mother had normal parturition ,20\% delivered with Low body weight, $10 \%$ over weight baby and delivered through lower section caeserian section due to Cephalo pelvic disproportion . In addition neonate developed neonatal pneumonitis with Respiratory Distress Syndrom (RDS) and lost their life . 10 mothers presented with jaundice during 2nd trimester and 7 neonates presented with neonatal jaundice (though no evidence of Rh incompatibility) .

\begin{tabular}{|l|l|l|l|}
\hline Particulars & Group A & Group B & Group C \\
\hline & & & \\
\hline Normal labour & None & $50 \%$ & None \\
\hline Premature water discharge & None & $10 \%$ & None \\
\hline Low birth weight baby & None & $20 \%$ & None \\
\hline Over weight baby & None & $10 \%$ & None \\
\hline Neonatal jaundice & None & $07 \%$ & None \\
\hline Pneumonitis with Respiratory & None & $06 \%$ & None \\
\hline distress syndrome & & & \\
\hline Maternal jaundice & None & $07 \%$ & None \\
\hline
\end{tabular}

\section{In General Debility (Chronic Fatigue Syndrome)}

All patients of general debility taking sugar free vitamin mineral had marked improvement with mean weight gain of $4 \pm 0.5 \mathrm{~kg}$ in 1 month whether patients taking sugar based preparation (group B) had mean weight gain of $1.5 \pm 0.75 \mathrm{~kg}$ and control group patient had weight gain of $1 \pm 0.25 \mathrm{~kg}$ weight gain.

No patients of group A had any untoward effect, exacerbation of presentation but $40 \%$ cases of group $\mathrm{B}$ had exacerbation of presentation and non responsive to continuing therapy whether non of control group had any exacerbation

\begin{tabular}{|l|l|l|l|}
\hline Particulars & Group A & Group B & Group C \\
\hline $\begin{array}{l}\text { Marked improvement in } \\
\text { Presentation }\end{array}$ & All & $67 \%$ & Non significant \\
\hline Weight gain & $3 \mathrm{Kg}$ & $1.5 \mathrm{Kg}$ & $1 \mathrm{Kg}$ \\
\hline Exacerbation of presentation & None & $40 \%$ & None \\
\hline
\end{tabular}

\section{In Hypertension}

Among patients of hypertension patient taking sugar free vitamin mineral adjuvant (group A) had marked improvement and sustained anti hypertensive effect with sustained normotensive state but patients of group B had circadian variation of blood pressure and ultimately non responsive to continuing anti hypertensive therapy in $32 \%$ in spite of administration at schedule time.

Whether no patients of hypertension of control group had non response to continuing antihypertensive therapy.

\begin{tabular}{|l|l|l|l|}
\hline Particulars & Group A & Group B & Group C \\
\hline $\begin{array}{l}\text { Circadian variation of blood } \\
\text { pressure }\end{array}$ & None & $42 \%$ & None \\
\hline Emergence of non response & None & $37 \&$ & None \\
\hline
\end{tabular}

\section{In Joint Pain}

All patients of group A had progressive relief of clinical presentation without any emergence of drug resistance while of group B only $80 \%$ had clinical improvement followed with non response in $48 \%$ while no significant effect was observed in patients of control group. 


\begin{tabular}{|l|l|l|l|}
\hline Particulars & Group A & Group B & Group C \\
\hline Progressive relief & All & $84 \%$ & $92 \%$ \\
\hline $\begin{array}{l}\text { Non responsiveness } \\
\text { to continuing therapy }\end{array}$ & None & $48 \%$ & None \\
\hline
\end{tabular}

\section{In Urinary Tract Infection}

All cases of group A had clinicopathological cure without any untoward effect whether group B $60 \%$ show initial improvement followed with relapse in 50\% cases and drug resistance to continuing drug in $40 \%$ cases while non of control group (group C) had any relapse or emergence of drug resistance.

\begin{tabular}{|l|l|l|l|}
\hline Particulars & Group A & Group B & Group C \\
\hline $\begin{array}{l}\text { Progressive } \\
\text { improvement }\end{array}$ & All & $60 \%$ & $93 \%$ \\
\hline Relapse & None & $50 \%$ & None \\
\hline $\begin{array}{l}\text { Emergence of drug } \\
\text { resistance }\end{array}$ & None & $40 \%$ & None \\
\hline
\end{tabular}

\section{In Recurrent pruritis}

All cases of group A had marked and significant clinicopathological cure without any untoward effect or adjuvant while group B though all had initial response but $47 \%$ patients presented with recurrence within a week while no relapse or drug resistance was noted in any case of control group.

\begin{tabular}{|l|l|l|l|}
\hline Particulars & Group A & Group B & Group C \\
\hline Progressive relief & All & $56 \%$ & $60 \%$ \\
\hline Progressive relief & None & $47 \%$ & None \\
\hline
\end{tabular}

\section{In Respiratory Disease}

All of group A had earliest relief of clinical presentation without any emergence of drug resistance or adversity while in group B out of 20 cases of pulmonary tuberculosis taking AKT and sugar based supplement, 7 had marked hepatotoxicity,5 developed drug resistance to continuing AKT due to emergence of mutant strain ,but no such effect was observed in any case of control group . Patients of group $\mathrm{A}$ and $\mathrm{C}$ had marked weight gain and early sputum conversion.

\begin{tabular}{|l|l|l|l|}
\hline Particulars & Group A & Group B & Group C \\
\hline $\begin{array}{l}\text { Progressive sputum } \\
\text { conversion }\end{array}$ & All & $59 \%$ & $64 \%$ \\
\hline Drug resistance & None & $20 \%$ & None \\
\hline Hepatotoxicity & None & $35 \%$ & $20 \%$ \\
\hline Weight gain & Progressive & None & None \\
\hline $\begin{array}{l}\text { Mean duration for } \\
\text { sputum conversion17 }\end{array}$ & 17 days & 39 days & 31 days \\
\hline
\end{tabular}

\section{In Surgical wound}

All cases of group A show progressive wound healing without any super infection, but 10 cases of group B though had initial regression and healing but had super infection and persistence of wound, control group shows no drug resistance or super infection.

\begin{tabular}{|l|l|l|l|}
\hline Particulars & Group A & Group B & Group C \\
\hline Super infection & None & 10 & None \\
\hline Drug resistance & None & 10 & None \\
\hline
\end{tabular}

\section{In Bone Injury}

99\% of group A had progressive bone healing and union with $1 \%$ failure due to mal reduction of the closed fracture without any suppuration or deformity, , whether group B only $43 \%$ had perfect bone union , $10 \%$ had suppuration and $2 \%$ needed amputation due to gangrene and septicaemia ,though none of control group had nay amputation or delayed healing .

\begin{tabular}{|l|l|l|l|}
\hline Particulars & Group A & Group B & Group C \\
\hline Progressive bone healing & $99 \%$ & $73 \%$ & $82 \%$ \\
\hline Suppuration & None & $10 \%$ & None \\
\hline Septicemia & None & $07 \%$ & None \\
\hline Delayed healing & None & $20 \%$ & $40 \%$ \\
\hline
\end{tabular}




\section{In Post Ligation Syndrome}

Group A patients of Post ligation syndrome presenting with various clinical manifestation but of group B $40 \%$ shows exacerbation of presenting manifestation while control group patient shows no such effect.

\begin{tabular}{|l|l|l|l|}
\hline Particulars & Group A & Group B & Group C \\
\hline $\begin{array}{l}\text { Exacerbation } \\
\text { presentation }\end{array}$ & None & $40 \%$ & None \\
\hline Weight gain & None & $80 \%$ & $20 \%$ \\
\hline Hypertension & None & $56 \%$ & $20 \%$ \\
\hline Exertional dyspnoea & relieved & increased & Non significant \\
\hline
\end{tabular}

\section{CONCLUSION}

Clinicopathological response in patients of varied clinical condition taking sugar free oral liquid therapeutics was more pronounced than patients taking sugar based oral liquid therapeutics or supplement.

Emergence of resistance to continuing therapeutics was common in patients taking sugar based oral liquid therapeutics or adjuvant.

Persistence or relapse and recurrence of the presenting feature was common to patients taking sugarbased formulation but uncommon among patients taking sugar free adjuvant or therapeutics.

Fungal super infection was more common with sugar based oral liquid therapeutics or adjuvant.

\section{DISCUSSION}

For patient's compliance liquid oral therapeutics in palatable base is a need for neonates to geriatrics specially in children and female patients. In addition, declining self-defence and increasing organ toxicity due to presence of non nutrient toxic dietary constituents poses threat to normal human physiology resulting in various dreadest illness.

Present study affirm that Non sugar based oral liquid preparation proves better than sugar based oral liquid preparation in achieving clinical cure, duration of therapy and checking relapse, recurrence, resistance, super infection and emergence of drug resistance as control group also reveals absence of these untoward effects .

Thus, can be concluded that sugar part of the liquid oral preparation interferes with intestinal $\mathrm{pH}$, alters absorption of the therapeutics and interferes with minimum inhibitory concentration (MIC) required, thus create drug resistance. Continuing Or persistent infection deprive immune modulators activity thus decline the self-defence.

Thus, at the cost of palatability patient's self-defence cannot be compromised and this study requires an extensive exploration in the present context of changing dietary structure.

\section{REFERENCES}

[1] Shankar ,A; Shankar ,M; Bhave ,S; and Khan AK, Effects of sugar based and sugar free vitamin mineral supplement in Pediatric practice ,Jr.A.C.P :60:04:102-104/2000

[2] Shankar A; Changing dietary constituent posing threat to life , The Current Therapeutics; 45:7:45-50/2000

[3] Fakrudin et al, The chronic fatigue syndrome, A comparative approach, Ann Internal Medicine ,121:913/1994

[4] Shankar,A; increasing incidence of hyperglycemia and glycosuria , a changed scenario of diabetes mellitus , Indian Jr of Endocrinology \& Metabolism 30:02:80-83/2001

[5] Steele ,L etal The Epidemiology of CFS ;105:835:198

Citation: Dr. Avinash Shankar, et.al. (2019). “Comparative Evaluation of Sugar based versus sugar free Oral liquid preparation in Medicare”. International Journal of Clinical Chemistry and Laboratory Medicine (IJCCLM), 5(2), pp. 13-18, DOI: http://dx.doi.org/10.20431/2455-7153.0502003.

Copyright: (C) 2019 Authors. This is an open-access article distributed under the terms of the Creative Commons Attribution License, which permits unrestricted use, distribution, and reproduction in any medium, provided the original author and source are credited. 